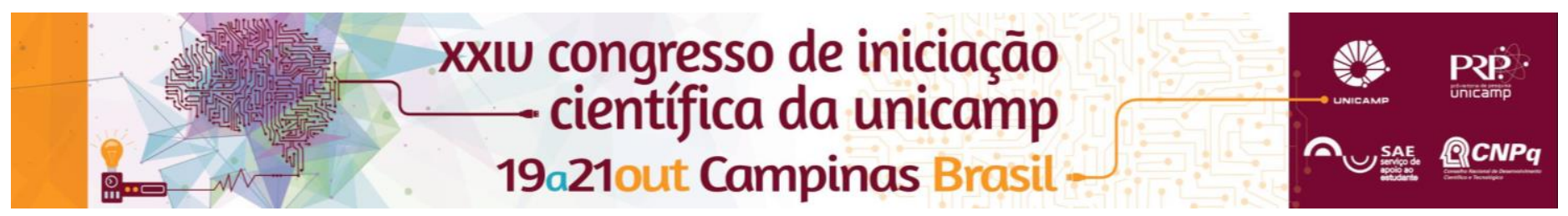

\title{
Avaliação da incidência de Salmonella em tomates maduros comercializados no Estado de São Paulo.
}

\author{
Fernanda G. Capraro, Heice S. L. Moraes*, Thais G. Magri, Ana Carolina B. Rezende, Anderson S. Sant'Ana.
}

\section{Resumo}

Surtos envolvendo Salmonella spp equivalem a cerca de $40 \%$ dos casos de DVA notificados no Brasil. Por isso, o presente estudo tem por objetivos: i) Avaliar a incidência de Salmonella em tomates maduros de variedades nacionais; ii) Caracterizar (fenotípica e genotipicamente) as cepas isoladas das amostras e determinar o perfil genético mais prevalente, justificando-se pela inexistência de dados sobre a incidência e características de cepas Salmonella em tomates para consumo "in natura" no Brasil.

\section{Palavras-chave:}

tomate, Salmonella, microbiologia.

\section{Introdução}

O consumo de tomate, seja ele fresco ou processado vem aumentado consideravelmente nos últimos anos devido a busca por praticidade e por alimentos mais saudáveis (Carvalho e Pagliuca, 2007).

A qualidade microbiológica dos vegetais e frutas tem sido objeto de diversas pesquisas ao redor do mundo e diversos pátogenos tem sido isolados destes produtos, como E. coli e Listeria spp (Lin et al., 1996), e Salmonella spp (Saleh et al., 2003).

Diferentes causas podem explicar incidência de salmonelose a partir do consumo de vegetais, e em particular, de tomates de mesa. As práticas adotadas do plantio até o manuseio concorrem para a contaminação destas frutas por microrganismos provenientes de diversas origens como o solo, ar, água, vetores, manipulação humana e o esterco usado como adubo. Nas etapas pós-colheita, pode haver a disseminação da contaminação através da água de resfriamento contaminada, por exemplo.

$\mathrm{Na}$ produção de tomate e seus derivados, há dois segmentos distintos: o tomate "rasteiro", que possui grande contato com solo, tanques de transporte e água de qualidade microbiológica questionável, tem como destino produtos industrializados, passando por processos térmicos; já o tomate "tutorado ou envarado" é produzido sob condições higiênicas mais rigorosas e controladas, sendo destinado para o consumo "in natura", não havendo nenhum tratamento que garanta a eliminação de patógenos de importância para alimentos. Houve quatro grandes surtos envolvendo Salmonella spp nos Estados Unidos entre 2005 e 2006, indicando a sua transmissibilidade por meios vegetais (MMWR, 2007). Estando o Brasil, com uma crescente importância no agronegócio mundial, o que leva a necessidade do país de possuir dados científicos referentes aos perigos associados aos diferentes tipos alimentos, de maneira a evitar que barreiras comerciais injustificadas sejam adotadas, além de ser uma questão de saúde pública e otimização dos recursos industriais.

\section{Resultados e Discussão}

Foram analisadas 240 amostras de diferentes espécies, adquiridas em mercados da região de Campinas.
Obteve-se, entretanto, duas colônias de uma única amostra que aglutinaram o soropolivalente, e estas cepas estão sendo confirmadas por sorologia na Fundação Oswaldo Cruz (FIOCRUZ, Rio de Janeiro, RJ). Porém, destaca-se que apesar de não se ter detectado Salmonella, estudos devem ser conduzidos para avaliar se tal patógeno pode se multiplicar e/ou sobreviver nos tomates que contenham diferentes $\mathrm{pH}$ e teor de sólidos solúveis.

\section{Conclusões}

Nas etapas de pré-colheita e pós-colheita o tomate pode ser contaminado por Salmonella. Apesar disso, no presente estudo, colônias presuntivas de Salmonella foram isoladas de somente uma amostra, indicando que as condições de produção e comercialização parecem ter sido adequadas. Apesar disso, práticas higiênicas devem ser adotadas, já que dependendo do $\mathrm{pH}$ e Brix, a Salmonella pode, inclusive se multiplicar em tomates.

\section{Agradecimentos}

Agradeço ao Prof. Dr. Anderson Sant'Ana, pela orientação neste projeto, à Monyca Dias Rocha, Veronica Ortiz Alvarenga, e demais membros do Laboratório de Microbiologia Quantitativa de Alimentos do DCA (FEA, UNICAMP) pelo apoio. Agradeço à Beatriz Oliveira Corte por representar o projeto no Congresso.

Carvalho, J.L. Pagliuca, L.G. (2007). Tomate, um mercado que não pára de crescer globalmente. Hortifruti Brasil, Jun., 6-14.

Lin, C.M., Fernando, S.Y., Wei, C. (1996). Occurrence of Listeria monocytogenes, Salmonella spp, Escherichia coli and E.coli 0157:H7 in vegetable salads. Food Control, v.7, n.3, p.135-140.

MMRW (2007). Multistate Outbreaks of Salmonella Infections Associated With Raw Tomatoes Eaten in Restaurants in United States, 2005-2006. JAMA. 298(15):1753-1755.

Salleh, N.A., Rusul, G., Hassan, Z., Reezal, A., Isa, S.H., Nishibuchi, M., Radu, S. Incidence of Salmonella spp in raw vegetables in Selangor, Malaysia. Food Control, v.14, n.7, p.475-479, 2003. 